\title{
Complexity of vaginal microflora as analyzed by PCR denaturing gradient gel electrophoresis in a patient with recurrent bacterial vaginosis
}

\author{
ESTELLE DEVILLARD ${ }^{1,2}$, JEREMY P. BURTON ${ }^{3}$, \& GREGOR REID GR $^{1,2}$ \\ ${ }^{1}$ Canadian Research and Development Centre for Probiotics, The Lawson Health Research Institute, London, Ontario, \\ Canada, ${ }^{2}$ Department of Microbiology and Immunology, University of Western Ontario, London, Ontario, Canada, and \\ ${ }^{3}$ BLIS Technologies, Centre for Innovation, University of Otago, Dunedin, New Zealand
}

\begin{abstract}
Objective: Gardnerella vaginalis has long been the most common pathogen associated with bacterial vaginosis (BV). We aimed to test our hypothesis that symptoms and signs of BV do not necessarily indicate colonization by this organism, and often will not respond to standard metronidazole or clindamycin treatment.

Methods: Using a relatively new molecular tool, PCR denaturing gradient gel electrophoresis (DGGE), the vaginal microflora of a woman with recalcitrant signs and symptoms of BV was investigated over a 6-week timeframe.

Results: The vagina was colonized by pathogenic enterobacteriaceae, staphylococci and Candida albicans. The detection of the yeast by PCR-DGGE is particularly novel and enhances the ability of this tool to examine the true nature of the vaginal microflora. The patient had not responded to antifungal treatment, antibiotic therapy targeted at anaerobic Gram-negative pathogens such as Gardnerella, nor daily oral probiotic intake of Lactobacillus rhamnosus GG. The failure to find the GG strain in the vagina indicated it did not reach the site, and the low counts of lactobacilli demonstrated that therapy with this probiotic did not appear to influence the vaginal flora.

Conclusions: BV is not well understood in terms of its causative organisms, and further studies appear warranted using non-culture, molecular methods. Only when the identities of infecting organisms are confirmed can effective therapy be devized. Such therapy may include the use of probiotic lactobacilli, but only using strains which confer a benefit on the vagina of pre- and postmenopausal women.
\end{abstract}

Key words: PCR-DGGE, bacterial vaginosis, vaginal microflora, diagnosis, probiotics

\section{Introduction}

Although bacterial vaginosis $(\mathrm{BV})$ is one of the most common gynecological problems encountered by primary care physicians and gynecologists, diagnostic tools are neither optimal nor convenient. The disease often presents in asymptomatic form, and is detected by the dominance of Gram-negative anaerobic bacteria [1], and in some cases aerobic bacteria [2], replacing the lactobacilli flora found in healthy women. Studies in the last decade have established that $\mathrm{BV}$ can be associated with infective complications, such as preterm labor, post-surgical sepsis and an increased risk factor of acquisition of sexually transmitted diseases including HIV [1, 3-5]. The infections frequently recur after antibiotic treatment. Indeed, standard therapy with metronidazole or clindamycin, administered intravaginally or orally, is followed by relapse in approximately $30 \%$ of cases, within 3 months [6]. Arguably, the inability to prevent relapses reflects a lack of understanding of the etiology and microbiology of BV.

The diagnosis of BV is based upon symptoms and signs including vaginal irritation, discharge and fishy odor, followed by microscopic examination of wet mounts. Amsel's criteria [7] or Nugent score [8] determinations, based on microscopic observations of swabs, remain the most widely used tests to diagnose BV. However, these are limited and do not identify the pathogens, which are presumed to be Gardnerella and other species such as Mobiluncus $[9,10]$.

Microbiological techniques, such as bacterial cultivation in combination with accurate molecular identification, have aided epidemiological investigation of $\mathrm{BV}$, but they are logistically demanding for routine analysis. In addition, because of anaerobic and

Correspondence: G. Reid, Canadian Research and Development Centre for Probiotics, The Lawson Health Research Institute, 268 Grosvenor Street, London, Ontario N6A 4V2, Canada. Tel: 519646 6100. Fax: 5196466031. E-mail: gregor@uwo.ca

ISSN 1064-7449 print/ISSN 1098-0997 online (C) 2005 Taylor \& Francis Group Ltd DOI: $10.1080 / 10647440400025504$ 
nutritional requirements, a large proportion of vaginal microorganisms are difficult to cultivate and some of them still remain to be cultivated [11]. The use of molecular techniques, based on polymerase chain reaction (PCR) and amplification of $16 \mathrm{~S} \mathrm{rDNA}$ seems to represent a rapid and reliable way to identify microorganisms. The combination of PCR and denaturing gradient gel electrophoresis (DGGE) allows the identification of a high number of bacterial species in the complex ecosystems of the human body [11-13]. DGGE has been successfully used for examination of the vaginal flora, including detection of Gardnerella and so far uncultured species such as Lactobacillus iners $[11,13]$. In the present study, we demonstrate the complexity of the microflora of a woman with recurrent, symptomatic BV which had not been resolved by previous antibiotic or probiotic therapy.

\section{Materials and methods}

\section{Subject}

A postmenopausal 51-year-old woman (SB) presented with an 18-month history of recurrent BV not resolved by various medications (standard treatment with metronidazole, clarithromycin, antifungals such as fluconazole and antiseptic solutions such as hydrogen peroxide and betadine). She reported having used home-made yogurt and Lactobacillus rhamnosus GG $\left(10^{10}\right.$ cells per dose, Culturelle,USA) vaginally and orally, with no detectable improvement with any of the listed regimens. At the time of the study, the patient was not receiving any hormones or antibiotics, but was still ingesting Lactobacillus rhamnosus GG, one dose daily. Her diagnosis included three of the four Amsel criteria [7], namely vaginal irritation, discharge, elevated $\mathrm{pH}>4.5$ and presence of clue cells in vaginal swab. She signed an informed consent document approved by the Ethics Review Board at the University of Western Ontario.

\section{Collection procedure}

Vaginal swabs were collected by the subject each week for 6 consecutive weeks. The swabs were immediately placed in a transport medium (NCS Diagnostics) and sent to our laboratory for analysis. Smears on microscope slides were Gram-stained and then scored by the method of Nugent et al. [7]: grades 0 to 3 (normal, N), 4 to 6 (intermediate, I) and 7 to 10 (high-grade bacterial vaginosis, BV).

\section{Extraction of DNA}

Swabs were vigorously agitated in $1 \mathrm{ml}$ of phosphatebuffered saline (PBS, pH 7.5), and microbial cells were pelleted by centrifugation $(10000 \mathrm{~g}, 5 \mathrm{~min})$, and washed once in PBS. Microbial DNA was extracted using Instagene Matrix (Bio-Rad Laboratories, Hercules, CA, USA) according to the manufacturer's instructions.

\section{PCR amplification of DNA and DGGE}

Amplicons of ribosomal bacterial DNA were obtained as described previously by Burton and Reid [7]. Briefly, $2 \mu \mathrm{l}$ of DNA extracted from the swabs were used as the template of the PCR reaction. The primers used were either eubacterial primers ( $5^{\prime}$-ACTCCTACGGGAGGCAGCAG-3', 5'-GTATTACCGCGGCTGCTGGCAC-3') in the case of amplification of all ribosomal eubacterial DNA, or lactobacillus-specific primers (5'-AGCAGTAGGGAATCTTCCA-3'， 5'-CATGTGTAGCGGTGRAAT-3') in the case of the amplification of this specific genus DNA. For each pair of primers, the forward primer carried a GC clamp (40 extra bases, mostly $\mathrm{G}$ and $\mathrm{C}$ ) at its $5^{\prime}$ end.

Preparation of DGGE gel gradients and electrophoresis was carried out according to the manufacturer's guidelines for the D-Code ${ }^{\mathrm{TM}}$ Universal Detection System of Bio-Rad. A $100 \%$ solution was taken as a mixture of $7 \mathrm{M}$ urea and $40 \%$ formamide. The concentrations of polyacrylamide and denaturant were $8 \%$ and $30-50 \%$, respectively. PCR products were mixed with $2 \times$ loading buffer ( $0.05 \%$ bromophenol blue, $0.05 \%$ xylene cyanol, $70 \%$ glycerol) and loaded into the wells. Gels were run at $130 \mathrm{~V}$ in $1 \times$ TAE $(40 \mathrm{mM}$ Tris, $20 \mathrm{mM}$ acetic acid, $1 \mathrm{mM}$ EDTA, $\mathrm{pH}$ 8.0). After electrophoresis, gels were stained for $20 \mathrm{~min}$ in $5 \mu \mathrm{g} / \mathrm{ml}$ of ethidium bromide and de-stained for $10 \mathrm{~min}$ in $1 \times$ TAE. Gels were visualized by ultraviolet transillumination.

\section{Band excision from DGGE gels, re-amplification and sequencing}

DGGE gel bands were excised using a sterile scalpel, washed once in $1 \times$ PCR buffer and incubated in of the same buffer overnight at $4^{\circ} \mathrm{C} ; 5 \mu \mathrm{l}$ of the buffer solution formed the template for PCR amplification. Re-amplification was conducted using either the eubacterial or lactobacilli PCR primers (with no 'GC clamps') depending on the primer set used in the DGGE, and with the same conditions as for the PCR preceding the DGGE analysis. Sequences of the reamplified fragments were determined by the dideoxy chain termination method (Sequencing Facility, John P. Robarts Research Institute, London, ON, USA). Analysis of the partial 16S rRNA sequences was conducted using the Genbank DNA database and the BLAST algorithm [14]. Identities of isolates were determined on the basis of the highest identity score. 


\section{Detection of Candida albicans by PCR}

Reference strain Candidia albicans ATCC 76615 was cultivated on Sabouraud glucose broth or agar (10 g peptone, $15 \mathrm{~g}$ glucose and $150 \mathrm{~g}$ agar in 1:1 distilled water, $\mathrm{pH}$ 6.8). The DNA was extracted from washed yeast cells in PBS by using Instagene Matrix (Bio-Rad Laboratories, Hercules, CA, USA) according to the manufacturer's instructions. The detection of the yeast was based on the amplification of the gene encoding a heat shock protein 90 gene fragment of 317 base pairs [15]. For the detection of $C$. albicans in the DNA extracted from the swabs, $2 \mu \mathrm{l}$ of template sufficed. The PCR reaction was the same as that described by Crampin and Matthews [15], except that a touchdown PCR protocol was used to increase amplification specificity. The annealing temperature was gradually decreased from $67^{\circ} \mathrm{C}$ to $55^{\circ} \mathrm{C}$ for 15 cycles. The detection limit of the yeast PCR assay was determined by using DNA extractions from known numbers of $C$. albicans cells.

\section{Results}

Nugent scores

No trichomonads were seen on the vaginal swabs. The six samples tested for Nugent scores showed clue cells and high scores between 9 and 10, confirming high-grade bacterial vaginosis. On microscopy differences were noticed between the six samples, in that the first sample showed a very high proportion of small Gram-negative rods, and in samples from following weeks the proportion of rods decreased as they were replaced by an increasing percentage of Gram-positive cocci.

$D G G E$ analysis of bacterial DNA from vaginal swabs using eubacterial-specific primers

Using DGGE analysis and DNA sequence analysis of the PCR products from eubacterial-specific primers targeting the $\mathrm{V} 2-\mathrm{V} 3$ region of the $16 \mathrm{~S}$ rRNA gene, it was possible to identify several bacterial species present in the vaginal swabs. Overall, seven different bacterial species were detected: Klebsiella oxytoca (fragments 1, 6, 9), Serratia fonticola (fragment 2), Citrobacter freundii (fragment 3), Morganella morganii (fragments 4, 7), Kluyvera ascorbata (fragment 5), Escherichia coli (fragment 10) and Staphylococcus epidermis (fragment 8) (Figure 1). The homology between the sequence obtained from the DGGE bands and the closest species from the database are given in Table I. The DGGE patterns for the first three samples seemed to be quite different to each other, showing an unstable ecosystem. However, for the last 3 weeks of analysis the
DGGE pattern appeared stable. The first sample contained three bacterial species: Klebsiella oxytoca, Serratia fonticola and Citrobacter freundii. On the second week, these three strains were no longer detectable and the microflora was dominated by a Morganella morganii strain. This organisms were then detected in all subsequent samples and represented the most intense band overall. Two additional bands, corresponding to Klebsiella oxytoca and Kluyvera ascorbata, were detected on week 3. Samples from weeks 4 to 6 showed similar patterns with four different bacterial species: Klebsiella oxytoca, Morganella morganii, Escherichia coli and Staphylococcus epidermis. These findings correlated with microscopic observations, namely a predominance of Gramnegative rods and Gram-positive cocci.

Interestingly, the sequencing of the DGGE bands did not reveal the presence of Gardenella vaginalis, Mycoplasma hominis, Mobiluncus sp. or Prevotella sp. which have generally been associated with cases of BV.

Using eubacterial primers, no DGGE bands corresponded to lactobacillus strains, which are normally present in the healthy vaginal microbiota. This absence of lactobacilli reflected the high Nugent scores of the subject's samples. However, use of Lactobacillus-specific primers (Figure 2) did detect five different Lactobacillus strains. These comprised Lactobacillus sp. GFTH5 (closest species being $L$. johnsonii), Lactobacillus johnsonii, Lactobacillus gasseri, Lactobacillus delbrueckii and Lactobacillus reuteri. The unidentified lactobacilli were dominant in each weekly sample, whereas Lactobacillus sp GFTH5 (L. johnsonii), L. delbrueckii, L. johnsonii and L. gasseri

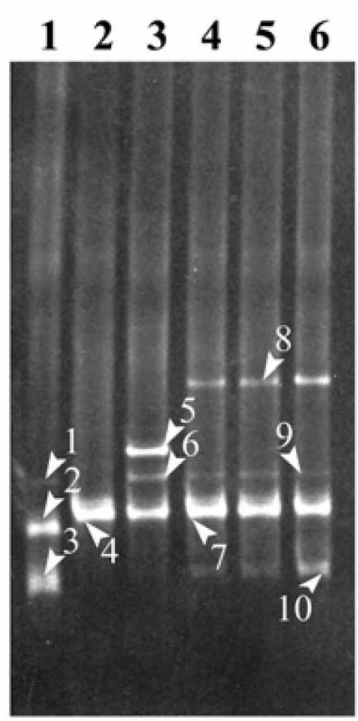

Figure 1. DGGE profiles of the total vaginal microbiota from the subject during the 6 weeks of study (lanes 1 to $6=$ weeks 1 to 6 ). See Table I for bacterial species associated with the arrowed bands shown here. 
Table I. BLAST analysis of vaginal bacterial and lactobacilli 16 SrRNA sequences of excised fragments from DGGE gels. + : band detected on the DGGE gel, - : band not detected on the DGGE gel, +/-: weak signal on the DGGE gel.

\begin{tabular}{|c|c|c|c|c|c|c|c|c|}
\hline Species & Homology & $\begin{array}{c}\text { Band } \\
\text { number }\end{array}$ & W1 & W2 & W3 & W4 & W5 & W6 \\
\hline Klebsiella oxytoca AF390083 & $87 \%$ & $1,6,9$ & + & - & + & + & + & + \\
\hline Serratia fonticola AF511435 & $100 \%$ & 2 & + & - & - & - & - & - \\
\hline Citrobacter freundii CFR233408 & $98 \%$ & 3 & + & - & - & - & - & - \\
\hline Morganella morganii AF461011 & $98 \%$ & 4,7 & - & + & + & + & + & + \\
\hline Kluyvera ascorbata AF310219 & $92 \%$ & 5 & - & - & + & - & - & - \\
\hline Escherichia coli CFT073 AE016770 & $98 \%$ & 10 & - & - & - & + & + & + \\
\hline Staphylococcus epidermidis AF397060DO & $92 \%$ & 8 & - & - & - & + & + & + \\
\hline Lactobacillus sp. GTH5 AF157033 & $95 \%$ & 1,6 & + & + & + & $+1-$ & - & + \\
\hline Lactobacillus johnsonii AY186044 & $95 \%$ & 3 & + & + & - & - & - & - \\
\hline Lactobacillus gasseri AY190619 & $94 \%$ & 2,5 & + & + & + & - & - & - \\
\hline Lactlbacillus delbruecki AF375917 & $92 \%$ & 4,8 & + & + & - & $+1-$ & + & + \\
\hline Lactobacillus reuteri LR16SRRI & $96 \%$ & 7 & - & - & - & $+1-$ & - & + \\
\hline
\end{tabular}

$\mathrm{W} 1=$ week 1 of sampling etc.

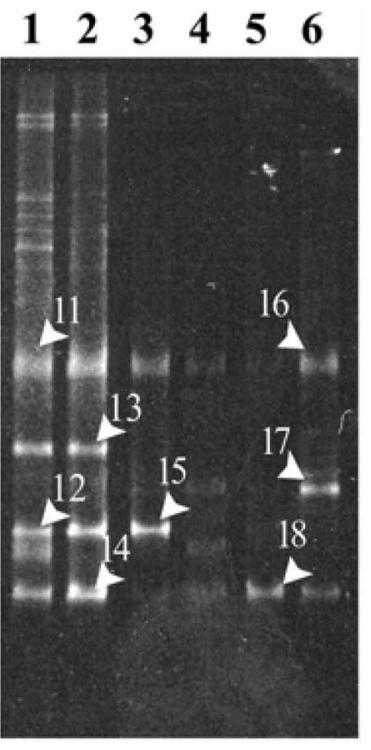

Figure 2. DGGE profiles of the vaginal lactobacilli population from the subject during the 6 weeks of the study (lanes 1 to $6=$ weeks 1 to 6 ). See Table I for Lactobacillus species associated with the arrowed bands shown here.

were detected in the second and third weeks only. The DGGE patterns on weeks 4 to 6 were very faint for lactobacilli and only Lactobacillus reuteri was identified on week 6 . Among the five sequences retrieved from the PCR-DGGE, none of them corresponded to the Lactobacillus rhamnosus GG strain present in the probiotic product that the subject was taking orally on a daily basis.

\section{Candida albicans detection}

The specificity of the PCR for detection of $C$. albicans was confirmed by DNA sequencing of the PCR products obtained with a $C$. albicans control strain.
The limit of detection was also determined using this PCR method, with a minimum of 100 cells being detected (Figure 3). Candida albicans was detected in weeks 1, 2, 4 and 5. The intensity of the PCR fragments from the samples from weeks 1,2 and 5 was very low, whereas that of fragments from the week 4 sample was intense (between 100 and 1000 $\mathrm{cfu} / \mathrm{ml}$, Figure 3).

\section{Discussion}

The present study of multiple vaginal samples from a woman with complicated vaginitis, provides valuable insight into difficult cases faced by gynecologists on a regular basis. The bacterial species detected by DGGE using eubacterial PCR primers were all potential urogenital pathogenic species $[9,16,17]$. Morganella morganii and Escherichia coli, detected in multiple samples, are not generally regarded as specific causes of BV [18], although they are well known for causing UTI [17] and E. coli have been associated with aerobic BV [2]. Staphylococcus epidermis was detected in the three last samples from the subject. This skin commensal is not normally a pathogenic species, but can take advantage of immunodeficiency, or abnormalities in the urogenital tract and can cause UTI [17]. Even although the patient was diagnosed with recurrent BV, no Gardnerella vaginalis were detected, nor were any of the other species normally associated with this disease, namely Mobiluncus sp., Mycoplasma hominis, and Prevotella sp. [1]. This finding demonstrates the complexity of complicated vaginitis and the difficulties in confirming its diagnosis. It also agrees with a recent study that showed that post-menopausal subjects not receiving estrogen replacement therapy can have BV without $G$. vaginalis [11]. Other studies show that non-gardnerella organisms cause BV [19] 


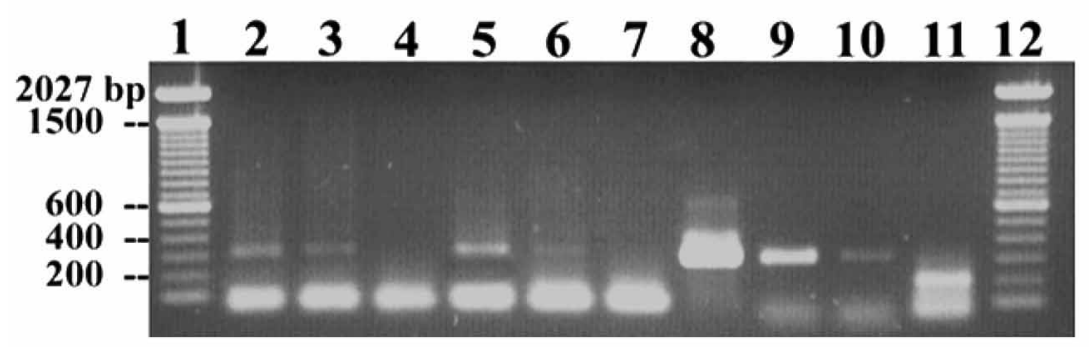

Figure 3. Detection of Candida albicans by PCR in the vagina of the subject during the six weeks of the study. Lanes 1 and $12=100 \mathrm{bp}$ ladder. Lanes 2 to $7=$ weeks 1 to 6 . Lanes 8 to $11=$ detection of $C$. albicans from a known number of yeast cells (respectively 10000 , 1000, 100 and $0 \mathrm{cfu} / \mathrm{ml})$.

and these bacteria can form dense biofilms [20] on vaginal cells, indicative of what is seen on clue cells examined under the microscope.

Given that BV treatment usually comprises antibiotics against anaerobic Gram negative bacteria, several scenarios are possible. Metronidazole treatment may have effectively eradicated infecting anaerobes prior to the patient being entered in our study, in which case the ability of Staphylococcus epidermis and Enterobacteriaceae to induce symptoms and signs of recurrence of $\mathrm{BV}$ is a finding that warrants further investigations. This scenario is less plausible as the subject ceased antibiotic use prior to entering the study. If the patient never had anaerobic pathogens as the prime cause of her BV presentation, then this might explain previous antibiotic failures, and it raises the question of how best to confirm diagnosis of the disease. While it is feasible that Gardnerella and other anaerobes may have been present and not detected by PCR-DGGE, it is unlikely over the six week study, and if these organisms were present in such low numbers it is doubtful that they played a major role in the patients' condition. Furthermore, the DGGE method has been shown by us to be a suitable method to detect even low levels of Gardnerella [11, 13]. It could be argued that we should have attempted to recover Gardnerella by culture, but given the difficulty to recover and quantify anaerobes by culture, and the obvious low numbers present if any, we did not feel that this would have significantly altered the overall findings.

DGGE analysis of eubacterial amplicons did not lead to the detection of any Lactobacillus species. However, PCR using species-specific primers did identify lactobacilli in low numbers. This suggests a deficiency in the Nugent scoring system which scores BV based upon the absence of lactobacilli. While these organisms may indeed be 'absent' under microscopy (which generally requires around $10^{4}$ bacteria per $\mathrm{ml}$ in the suspension being examined under the microscope), they may in fact not be totally absent from the vaginal vault. This offers hope for recovery of the patient, as stimulation of the indigenous lactobacilli (through use of prebiotics, or creation of a suitable microenvironment by exogenous lactobacilli application) [21] could lead to recovery and dominance of the lactobacilli flora. Studies have shown that select strains of Lactobacillus can colonize the vagina and inhibit the growth and adhesion of various pathogens [22-25]. The failure of Lactobacillus rhamnosus GG therapy to lead to its colonization of the vagina and correction of the BV, could have several explanations. Ingestion of this organism has failed in previous studies to make an impact on the urogenital flora and patient health [26, 27], while direct intravaginal application has not led to long term colonization [28]. On the other hand, the patient here is post-menopausal, and in such cases lactobacilli are often not present without estrogen replacement therapy [29], and it is possible that only select probiotic strains would colonize. The fact that lactobacilli were recovered from the vagina of this patient, supports the view that Lactobacillus rhamnosus GG [27] is not the most appropriate probiotic for patients with recurrent $\mathrm{BV}$ or chronic vaginitis.

Of the lactobacilli detected in the vagina, none were from the yogurt cultures consumed by the patient, and of those cultures only L. gasseri has been found to be somewhat common in postmenopausal subjects [11]. The most commonly isolated strain in healthy women after menopause, L. iners, was not detected in this subject. Understanding why certain lactobacilli exist in different subjects remains a topic requiring much additional investigation.

PCR proved to be an easy and reliable way to determine the presence of yeast, a common cause of vaginal infections $[15,30]$. The extent to which $C$. albicans, contributed to the patient's condition is unknown, but the levels in week 4 were consistent with a transient yeast infection. While the study was not designed to provide a clinical cure for the subject, it is possible that she will require mechanical, chemical and anti-microbial treatment as 
reported elsewhere [6] at least a new approach to eradicating the isolated pathogens.

In summary, this study showed that molecular techniques represent an excellent tool to identify the pathogenic microorganisms involved in recurrent BV. Current microscopic wet mount analysis is useful to assess the level of infection, while culture may not be sufficient to adequately guide effective treatment. Until techniques such as PCR-DGGE and sequencing become widely available in diagnostic laboratories, and routine microbiology laboratories more effectively recover fastidious anaerobes from vaginal swabs, physicians will not have adequate information to best diagnose and treat their patients. In this present case, use of metronidazole or clindamycin, the standard agents to treat $\mathrm{BV}$, will only result in failure.

\section{Acknowledgments}

We thank Dominique Lam for the staining and reading of slides. This study was part funded by Wyeth Ayerst Canada and NSERC Canada.

\section{References}

1. Sobel JD. Bacterial vaginosis. Annu Rev Med 2000;51: 349-56.

2. Donder GG, Vereecken A, Bosmans E, et al. Definition of a type of abnormal vaginal flora that is distinct from bacterial vaginosis: aerobic vaginitis. BJOG 2002;109(1):34-43.

3. Sewankambo N, Gray RH, Wawer MJ, et al. HIV-1 infection associated with abnormal vaginal flora morphology and bacterial vaginosis. Lancet 1997;350(9077):546-50.

4. Taha TE, et al. Bacterial vaginosis and disturbances of vaginal flora: association with increased acquisition of HIV. AIDS 1999;12(13):1699-1706.

5. Wiesenfeld HC, Hillier SL, Krohn MA, et al. Bacterial vaginosis is a strong predictor of Neisseria gonorroeae and Chlamydia trachomatis infection. Clin Infect Dis 2003;36: 663-8.

6. Papanikolaou EG, Tsanadis G, Dalkalitsis N, Lolis D. Recurrent bacterial vaginosis in a virgin adolescent: a new method of treatment. Infect 2002;30(6):403-4.

7. Amsel R, Totten PA, Speigel CA, et al. Nonspecific vaginitis. Diagnostic criteria and microbial and epidemiologic associations. Am J Med 1983;74:14-22.

8. Nugent RP, Krohn MA, Hillier SL. Reliability of diagnosing bacterial vaginosis is improved by a standardized method of Gram stain interpretation. J Clin Microbiol 1991;29: 297-301.

9. Cook RL, Redondo-Lopez V, Schmitt C, et al. Clinical, microbiological, and biochemical factors in recurrent bacterial vaginosis. J Clin Microbiol 1992;30(4):870-7.

10. Smayevsky J, Canigia LF, Lanza A, Bianchini H. Vaginal microflora associated with bacterial vaginosis in nonpregnant women: reliability of sialidase detection. Infect Dis Obstet Gynecol 2001;9(1):17-22.
11. Burton JP, Reid G. Evaluation of the bacterial vaginal flora of twenty postmenopausal women by direct (Nugent Score) and molecular (polymerase chain reaction and denaturing gradient gel electrophoresis) techniques. J Infect Dis 2002; 186:1777-80.

12. McCartney AL. Application of molecular biological methods for studying probiotics and the gut flora. Br J Nutr 2002;88 Suppl 1:S29-37.

13. Burton JP, Cadieux P, Reid G. Improved understanding of the bacterial vaginal microbiota of women before and after probiotic instillation. Appl Environ Microbiol 2003;69: 97-101.

14. Altschul SF, Gish W, Miller W, et al. Basic local alignment search tool. J Mol Biol 1990;215(3):403-10.

15. Crampin AC, Matthews RC. Application of the polymerase chain reaction to the diagnosis of candidosis by amplification of an HSP 90 gene fragment. J Med Microbiol 1993;39(3): 233-8.

16. Brook I. Microbiology and management of polymicrobial female genital tract infections in adolescents. J Pediatr Adolesc Gynecol 2002;15(4):217-26.

17. Ronald A. The etiology of urinary tract infection: traditional and emerging pathogens. Am J Med 2002;113 (Suppl 1A): 14S-19S.

18. Vu-Thien $\mathrm{H}$. Antibiotic sensitivity to isolated bacteria in pediatric urinary tract infections. Arch Pediatr 1998;5 (Suppl 3):266S-268S.

19. Mikamo H, Kawazoe K, Izumi K, et al. Bacteriological epidemiology and treatment of bacterial vaginosis. Chemotherapy 1996;42(1):78-84.

20. Reid G, Heinemann C, Howard J, et al. Understanding urogenital biofilms and the potential impact of probiotics. Methods Enzymol 2001;336;403-410.

21. Reid G, Bruce AW, Taylor M. Instillation of Lactobacillus and stimulation of indigenous organisms to prevent recurrence of urinary tract infections. Microecology Therapy 1995;23:3245.

22. Boris S, Barbes C. Role played by lactobacilli in controlling the population of vaginal pathogens. Microbes Infect 2000;2(5):543-6.

23. Dembele $T$, Obdrzalek V, Votava $M$. Inhibition of bacterial pathogens by lactobacilli. Zentralbl Bakteriol 1998;288(3): 395-401.

24. Reid G, Bruce AW. Selection of Lactobacillus strains for urogenital probiotic applications. J Infect Dis 2001;183 (Suppl 1):S77-80

25. Antonio MA, Hillier SL. DNA fingerprinting of Lactobacillus crispatus strain CTV-05 by repetitive element sequence-based PCR analysis in a pilot study of vaginal colonization. J Clin Microbiol 2003;41(5):1881-7.

26. Kontiokari T, Sundqvist K, Nuutinen M, et al. Randomised trial of cranberry-lingonberry juice and Lactobacillus GG drink for the prevention of urinary tract infections in women. BMJ 2001;322(7302):1571.

27. Colodner R, Edelstein H, Chazan B, Raz R. Vaginal colonization by orally administered Lactobacillus rhamnosus GG. Isr Med Assoc J 2003;5:767-9.

28. Cadieux P, Burton J, Kang CY, Gardiner G, Braunstein I, Bruce AW, Reid G. 2002. Lactobacillus strains and vaginal ecology. JAMA 287:1940-1941.

29. Raz R, Stamm WE. A controlled trial of intravaginal estriol in postmenopausal women with recurrent urinary tract infections. N Engl J Med 1993;329(11):753-6.

30. Wahyuningsih R, Freisleben HJ, Sonntag HG, et al. and rapid detection of Candida albicans DNA in serum by PCR for diagnosis of invasive candidiasis. J Clin Microbiol 2000;38(8):3016-21 


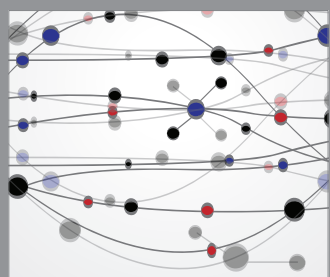

The Scientific World Journal
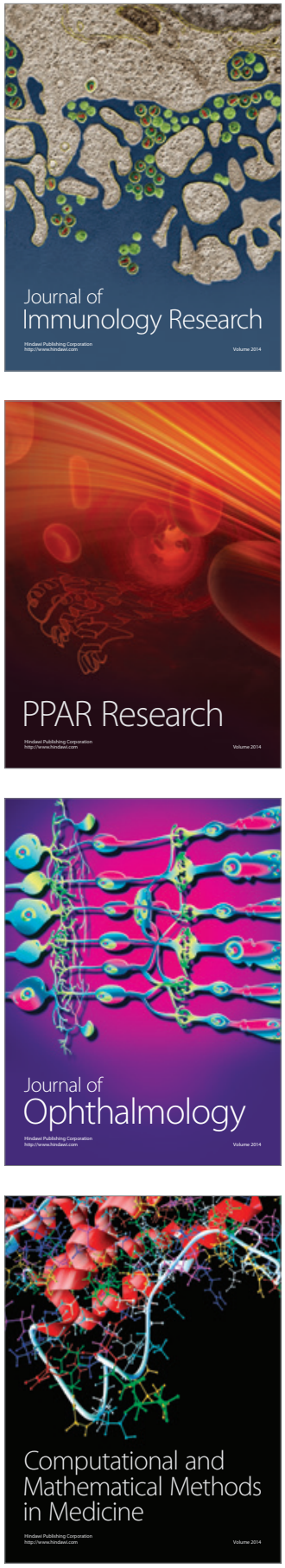

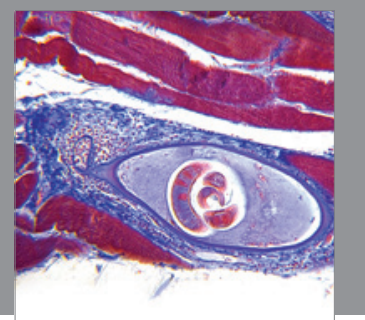

Gastroenterology

Research and Practice
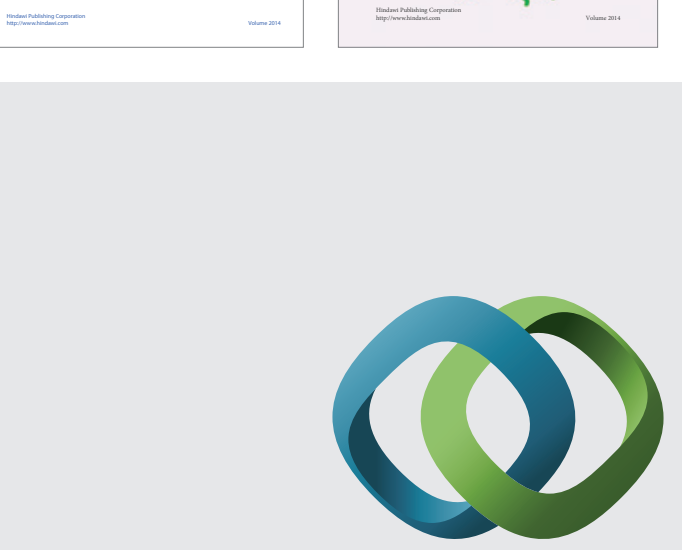

\section{Hindawi}

Submit your manuscripts at

http://www.hindawi.com
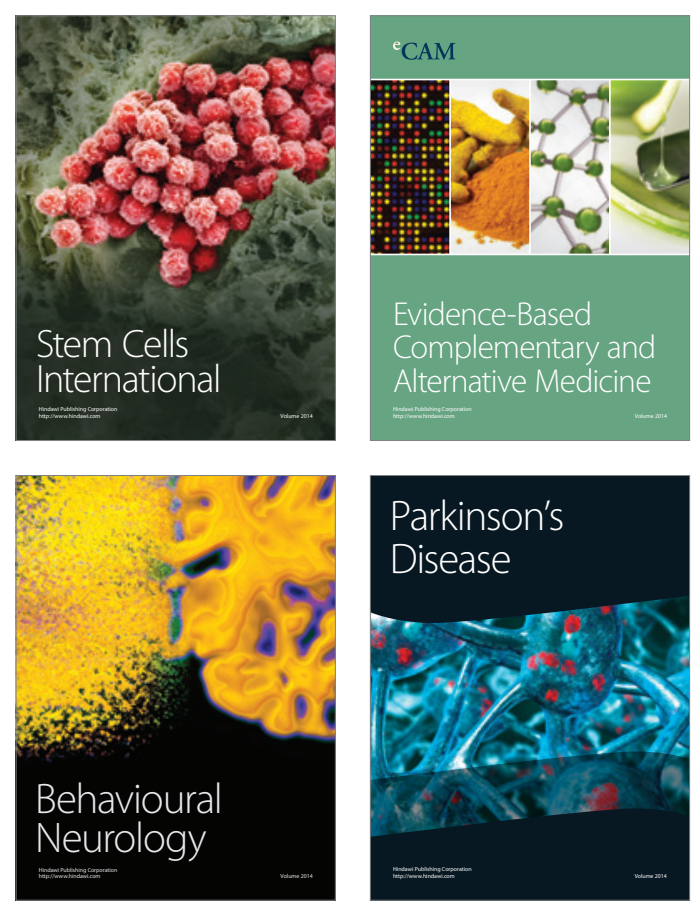

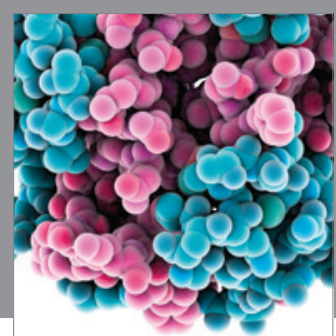

Journal of
Diabetes Research

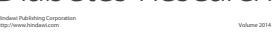

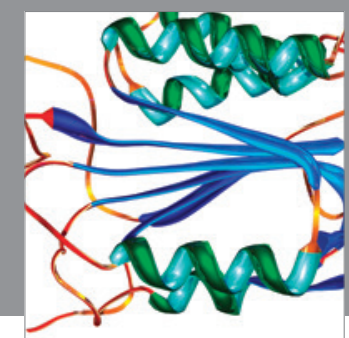

Disease Markers
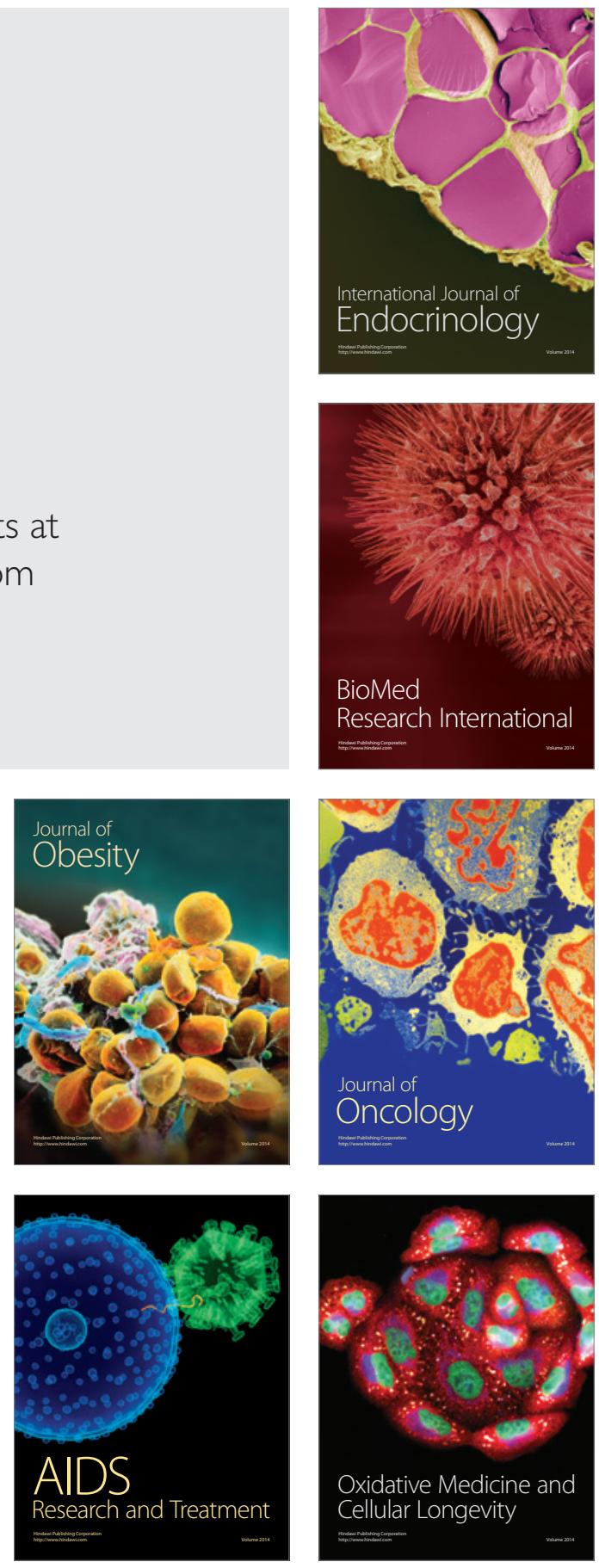